\title{
EI documentalismo gráfico en España y Estados Unidos en los años 80: Miguel Trillo y Mary Ellen Mark
}

\author{
Alicia PARRAS PARRAS \\ aparras@ccinf.ucm.es \\ Sección Departamental de Biblioteconomía y Documentación \\ Facultad de Ciencias de la Información \\ UCM-UCLA
}

Recibido: 05/05/2013

Aceptado: 20/05/2013

\section{RESUMEN \\ En el presente artículo, además de repasar las características y antecedentes del documentalismo fotográfico contemporáneo, veremos dos ejemplos del mismo que se produjeron en dos países muy distintos (Estados Unidos y España) en la misma época: los años ochenta del siglo XX. Se trata, en primer lugar, del trabajo de Mary Ellen Mark, quien apostó por un documentalismo en la línea de los concerned photographers, y de Miguel Trillo que fotografió a la juventud española de la década de los ochenta cuando las tribus urbanas representaban verdaderas identidades definidas dentro de una sociedad española ya inmersa en la democracia y la libertad de expresión. \\ Palabras clave: Fotografía documental, Mary Ellen Mark, documentalismo contemporáneo, Miguel Trillo. \\ Documentary photography in Spain and United States in the 80's: Miguel Trillo and Mary Ellen Mark}

\begin{abstract}
In this paper, besides reviewing the traits and the antecedents of contemporary documentary photography, two examples of this photographic genre will be seen. They took place in two very different countries (U.S. and Spain) at the same time: the eighties of the XX century. It is, firstly, the work of Mary Ellen Mark, who opted for a documentary on the line of the concerned photographers, and Miguel Trillo who photographed the Spanish youth when urban tribes real represented identities defined within a Spanish society immersed in democracy and freedom of expression.

Keywords: Documentary photography, Mary Ellen Mark, Contemporary documentary, Miguel Trillo.
\end{abstract}




\section{EL DOCUMENTALISMO FOTOGRÁFICO CONTEMPORÁNEO: CARACTERÍSTICAS Y ANTECEDENTES}

Margarita Ledo nos propone ciertas constantes en la fotografía documental. La primera de todas estas constantes es el referente real, es decir, la realidad que se quiere fotografiar y que no se puede intervenir de ningún modo, excepto a través del encuadre, luz, selección, etcétera ${ }^{1}$. Este realismo se convierte en una convención que produce, de cara al espectador, los efectos-verdad: eso es cierto, ha ocurrido. Y finalmente, todo ello nos lleva al efecto documental, que según Ledo se manifiesta por la consciencia del espectador y el modo de percibir las imágenes construidas según los cánones del documental porque, evidentemente, lo documental tiene también una cierta estética común, como todos los géneros fotográficos ${ }^{2}$.

Y aparte de la estética, la ética, el consabido punto donde el fotógrafo debe decidir si disparar su cámara o no, ¿hasta dónde se ha de documentar un suceso ya sea guerra, atentado, hambruna, etcétera? Sin ir más lejos, Oliverio Toscani, en los años noventa del siglo veinte se atrevió a fotografiar víctimas del SIDA en su lecho de muerte, convertirlas en reclamo publicitario para la firma Benetton y concienciar así a la ingente masa que consumía esa marca. Sin embargo, es famosa también la fotografía de Kevin Carter, y ganadora de un Pulitzer en 1994, de un niño famélico con un buitre detrás esperando ansioso el triste deceso. Con esta imagen, Carter fue acusado de no hacer nada para evitar el destino del niño y ello, unido a problemas personales, le empujó al suicidio ese mismo año aunque realmente aquel desnutrido niño protagonista de la foto no murió de hambre aquel día, sino en 2008 a causa de fiebres ${ }^{3}$.

En cualquier caso, se pueden deducir algunas características acerca de la fotografía documental:

1. Conciencia y consciencia por parte del fotógrafo de querer mostrar una realidad, de abrir un ojo, el diafragma de la cámara para captar una realidad determinada.

2. La variedad de los temas que la fotografía documental recoge. No hay temas buenos o malos sino que depende del enfoque con que se trate. En este artículo veremos dos ejemplos de una misma época y que son totalmente opuestos: Mary Ellen Mark y Miguel Trillo. Es el registro de jóvenes desde un enfoque y una realidad distinta.

\footnotetext{
${ }^{1}$ Probablemente esta sea la principal constante que diferencie a la fotografía documental de cualquier otro género fotográfico.

${ }^{2}$ LEDO, Margarita: Documentalismo fotográfico: Éxodos e identidad. Madrid, Cátedra. 1998 p. 61

${ }^{3}$ ROJAS, Alberto: Kong Nyong, el niño que sobrevivió al buitre ElMundo.es (2011) Disponible en Internetenhttp://www.elmundo.es/elmundo/2011/02/18/comunicacion/1298054483.html [Fecha de consulta: 16 de mayo de 2013]
} 
3. Vocación de futuro. Es decir, la fotografía documental sigue cumpliendo su función de ventana a una realidad concreta sin importar cuántos años hayan pasado desde que se tomaron las imágenes.

Parece lógico pues que, desde la aparición de la fotografía, esta fuese inmediatamente comprendida como el instrumento perfecto para registrar para la posteridad y dar a conocer todo aquello que hasta entonces tan solo podía ser visto in situ. Los propios fotógrafos enseguida lo entendieron así, y desde el comienzo de la actividad fotográfica, se dedicaron a ello. Según el catedrático Jorge Pedro Sousa los antecedentes más inmediatos del documentalismo fotográfico son: la fotografía de viajes y de curiosidades etnográficas de mitad del siglo XIX; las fotografías de Gardner, Timothy O`Sullivan y William Henry Jackson acerca de la conquista del Oeste de Estados Unidos; las imágenes que tomaron tanto Curtis como Vroman, a principios del siglo XX de los indios norteamericanos con su indumentaria típica (que para entonces, curiosamente, ya habían abandonado, y así registrar para la posteridad las costumbres y modos de vida de esos nativos americanos); las fotografías que se tomaron en el último tercio del siglo XIX en las colonias de África y Asia ${ }^{4}$ con distintas intenciones (comercial, divulgativa y para realizar "el inventario del mundo"); la obra de 1851 de Henry Mayhew London Labour and London Poor en el que dejaba constancia de los primeros efectos de la industrialización; las fotografías que Carlo Ponti tomó vendedores venecianos y las maravillosas vistas de la ciudad con el fin de venderlo como souvenir; y por último, algunos fotógrafos más conocidos y considerados no solo pioneros sino clásicos del documentalismo en particular y la fotografía en general: Jacob Riis y Lewis Hine ${ }^{5}$.

\footnotetext{
${ }^{4}$ Un bello ejemplo que cabe citar en cuanto a las fotografías de las colonias en Asia, son las realizadas en Filipinas durante el dominio español, y reunidas en el libro de Juan Guardiola El imaginario Colonial, fotografia en Filipinas durante el periodo español 1860-1898 Barcelona : Sociedad Estatal para la Acción Cultural Exterior de España, 2006; en esta recopilación podemos ser testigos de una documentación gráfica de excepción y contemplar, así, desde la vida cotidiana en la colonia hasta las formas de vida de los nativos o la organización administrativa y territorial.

${ }^{5}$ SOUSA, Jorge Pedro: Historia del fotoperiodismo occidental. Sevilla, Comunicación Social. 2003. Pág. 66
} 


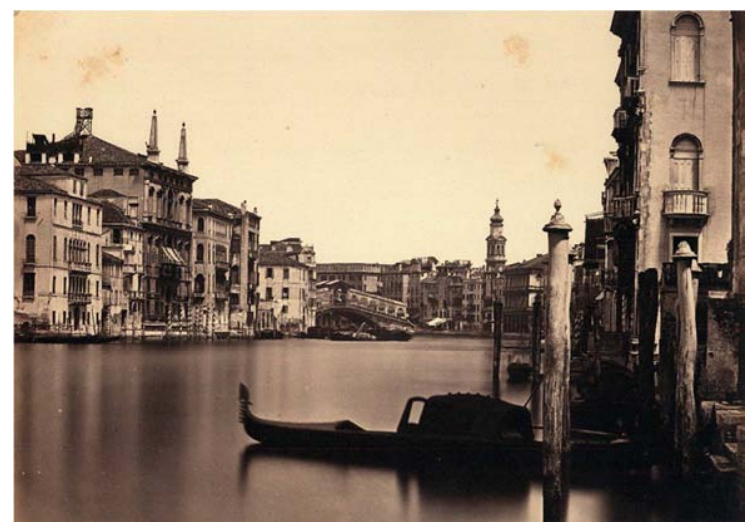

Carlo Ponti, Venezia

Jacob Riis comenzó trabajando como reportero policial; sin embargo, las lamentables condiciones y situaciones que iba encontrando por los barrios más miserables de Nueva York, principalmente en la zona oriental y el downtown de Manhattan, le hicieron iniciar su propia campaña personal ${ }^{6}$ para denunciar esta situación. Se dio cuenta de que con la palabra no bastaba y comenzó a fotografiar, utilizando el flash, hasta aquel momento poco utilizado, las situaciones de pobreza extrema en las que vivía la población. También acompañaba sus imágenes de comentarios directos con los que complementaba la imagen a fin de concienciar al receptor ${ }^{7}$.

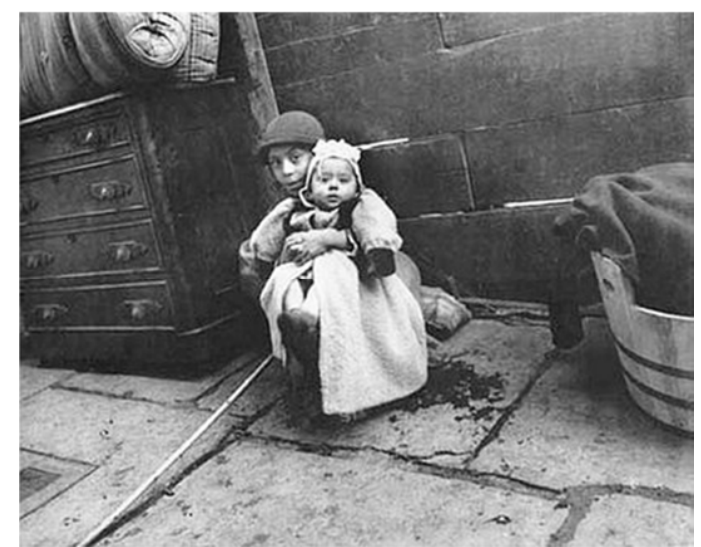

Jacob Riis, Minding the baby. Nueva York, 1890

${ }^{6}$ NEWHALL, Beaumont: Historia de la Fotografia. Barcelona, Gustavo Gili 2002, pág. 132.

${ }^{7}$ SOUGEZ, Marie Loup (coord.): Historia General de la Fotografia Madrid, Cátedra, 2007. Pág 455. 
En 1888, los dibujos realizados a partir de sus fotografías fueron publicados por el periódico Sun de Nueva York con el título Flashes from the Slums. Dos años después, en 1890 publicó su más famosa obra Cómo vive la otra mitad donde por primera vez, mostraba a la sociedad y a la clase media-alta neoyorkina cuál era la forma de vida de los más desfavorecidos. Sin embargo, no será hasta 1947 cuando Cómo vive la otra mitad y la figura de Jacob Riis alcance el reconocimiento social merecido, gracias a otro fotógrafo, Alexander Alland, quién realizó ampliaciones de los negativos originales y organizó una exposición en el Museo de la Ciudad de Nueva York. El propio Roosevelt, quien era conocedor de la obra de Riis, trabó cierta amistad con el fotógrafo antes de ser presidente de los Estados Unidos, e impresionado dijo de él que era el mejor estadounidense que había conocido nunca ${ }^{8}$. Lo cierto es que Riis logró influirle hasta tal punto que Roosvelt, una vez en el poder, puso en marcha tras la Gran Depresión el famoso New Deal en el que promovió reformas a nivel rural que fueron posteriormente documentadas con las fotografías de la Farm Security Administration (FSA), en cuyas filas se encontraban fotógrafos como Dorothea Lange 9 .

También de la misma época que Jacob Riis pero interesado en una perspectiva más sociológica de la fotografía nos encontramos a Lewis Hine (1874-1940). Este estadounidense estudió sociología en las universidades de Chicago, Nueva York y Columbia y utilizó la, por entonces, novedosa técnica de la fotografía para apoyar sus investigaciones acerca de la sociedad norteamericana. Hine pensaba que la fotografía tenía que ser parte del arte y no de la ciencia por lo que, aunque realizaba sus fotografías para apoyar sus estudios científicos, procuraba que las imágenes que tomaba fuesen artísticas. De este modo, Hine tomaba primeros planos en los que los retratados miraban a la cámara de forma directa para llegar al espectador, y utilizaba composiciones preparadas que parecen sacadas de una obra pictórica. Ello no impidió que estas imágenes reflejasen la miseria de las clases más desamparadas de la sociedad neoyorkina, o el esfuerzo y el peligro que suponían algunos trabajos de la época.

Hine comenzó fotografiando hacia 1905 a los emigrantes que llegaban a Ellis Island procedentes de Europa. Lo más sobresaliente de estas fotografías es la captura de la personalidad de cada uno de estos emigrantes. A veces altivos y desafiantes y otras veces, preocupados y descolocados tras el largo viaje. En 1908 abandonó completamente la docencia para dedicarse a la fotografía y amplió sus reportajes sobre Ellis Island, fotografiando esta vez el hacinamiento y las miserables condiciones de trabajo de los emigrantes recién llegados. También en 1908 es cuando Hine comienza a trabajar para el Child Labor Comittee que precisamente se creó para intentar erradicar el trabajo infantil. De nuevo, las instantáneas son absolutamente directas a la vez que conmovedoras: niños que han perdido alguna extremidad o que

\footnotetext{
${ }^{8}$ DEWEY, Donald: Jacob Riis: Social Reformer. Scandinavian Review, ISSN 0098-857X, 10/2006, Volumen 94, Número 2, p. 23

${ }^{9}$ SOUGEZ, Marie Loup (coord.) Op. cit, pág 455.
} 
trabajan en las peores condiciones la mayor parte del día. Hine, sociólogo de profesor, acompañaba todas sus fotografías de datos tales como nombre, altura o peso y también de texto ${ }^{10}$. Así, se anticipó a los fotógrafos del reportaje de los años veinte ${ }^{11}$. $\mathrm{Su}$ siguiente trabajo lo realizaría fuera de las fronteras de los Estados Unidos pues viajó hasta Europa para fotografiar a los refugiados obligados a desplazarse tras la I Guerra Mundial en 1919. Esta experiencia le marcaría hasta el punto de renovar su lenguaje fotográfico: ya no solo busca la dignidad del retratado sino también la vitalidad que le impulsa a seguir hacia delante incluso en las condiciones más adversas.

De regreso en Estados Unidos comenzó a fotografiar a obreros de diversos gremios: construcción, metalurgia o electricistas que ensalzan la dignidad y el valor del trabajo. Son las fotos recogidas en su serie Retratos laborales. Hine es también el autor de las famosas e impresionantes fotografías que documentan la construcción del Empire State Building de Nueva York, en ese momento, 1930-1931, símbolo de esperanza tras el Crack del 29. Estas fotos y los Retratos laborales fueron recogidos en su obra de 1932 Men at work, que, por cierto, fue el único libro que Hine publicó ${ }^{12}$.

Según Hine, sus fotografías eran fotointerpretaciones, es decir, imágenes subjetivas, en las que, como ya hemos dicho se captaba toda la personalidad del sujeto, artísticas pero a la vez críticas ya que resaltaban las maltrechas condiciones de vida de los más desfavorecidos. El final de su vida se redujo a la miseria que el mismo había fotografiado años antes para presionar a los poderes públicos. Murió casi olvidado y sin obtener el reconocimiento que hoy en día, muchos años después, sí tiene por parte de la sociedad. El propio Hine dijo acerca de su trabajo: Quise hacer dos cosas. Quise mostrar lo que habia que corregir; quise mostrar lo que había que apreciar. ${ }^{13}$

Otro de los trabajos que supone una gran influencia para el fotodocumentalismo contemporáneo es el que desempeñó la fotógrafa Dorothea Lange (1895-1965) a partir de 1935 para la Farm Security Administration (FSA) que formaba parte del Department of Agriculture. Este departamento fue creado para ayudar a los granjeros más afectados por la crisis posterior al Crack del 29 estadounidense ${ }^{14}$ y los efectos de la Gran Depresión. Así, Lange documentaba a través de sus fotografías la lamentable situación en la que las familias de granjeros se encontraban y la terrible situación de depresión económica que les empujó a la emigración hacia otras zonas menos afectadas. Sin embargo, en un principio Lange fue contratada junto a otros fotógrafos para retratar a estos granjeros en una "actitud positiva". En realidad pasó de

${ }^{10}$ Folleto exposición Lewis Hine. Fundación MAPFRE. Febrero 2012

${ }^{11}$ SOUGEZ, Marie Loup (coord.) Op. cit, pág 456.

${ }^{12}$ Folleto exposición Lewis Hine. Op. cit pág 111.

${ }^{13}$ Ibídem

${ }^{14}$ GOLDEN, Reuel: Fotoperiodismo. Los fotógrafos de noticias más importantes del mundo. Madrid, Libsa, 2011. 
fotografiar a las familias más ricas de San Francisco a las más desgraciadas tras su paso del retrato al género documental. Este cambio de rumbo de su trabajo coincidió con el comienzo de una nueva etapa en su vida personal: se divorció de su marido, el pintor Maynard Dixon y se casó con el profesor de economía de la Universidad de California, Paul Schuster Taylor. Además de una relación personal les unía el afán por mostrar al resto de la sociedad norteamericana la situación de pobreza rural generada por las migraciones en busca de una vida mejor. Así ambos llevarán a cabo un profundo estudio, que duraría seis años en el que Taylor recogía la información a través de entrevistas y Lange mediante sus fotografías.

Si tuviésemos que elegir la foto que mejor define el trabajo de Dorothea Lange sería, por excelencia, "Madre Migrante" 15 , la cual se convirtió en icono de la Gran Depresión norteamericana. Fue tomada en marzo de 1936 en Nipomo, California, y en ella aparece una madre con sus tres hijos, uno de ellos aún bebé. La mirada perdida de la madre y la expresión de su boca, una mezcla de hastío, angustia e incertidumbre hacen de esta imagen la perfecta muestra de la pobreza y la miseria a la que millones de personas se vieron sometidas.

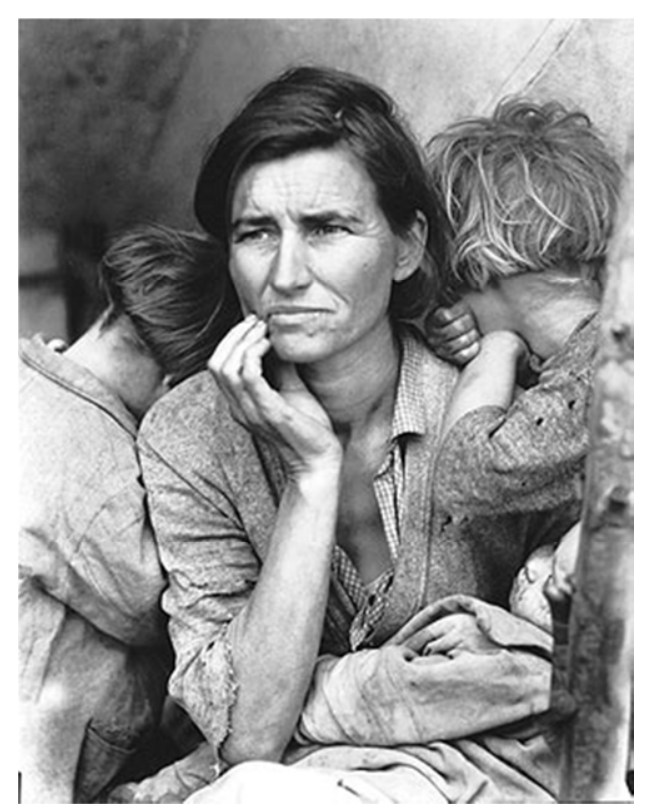

Dorothea Lange, Madre Migrante, 1936

Sin embargo, como ocurre con la mayoría de las fotos ícono, se trata de una instantánea polémica. En primer lugar porque se dice que Lange dirigía sus fotos. Es decir, indicaba a aquellos que iban a posar para ella qué postura adoptar o hacía

\footnotetext{
${ }^{15}$ También conocida como Migrant Madonna.
} 
dónde dirigir su mirada. Además, tras revelar los negativos, había un dedo en primer plano que Lange eliminó tras retocar el negativo. Stryker, quién la contrató para formar parte del staff de la FSA (Farm Security Administration) no estuvo de acuerdo con el posterior retoque ya que decía que "manipulaba la verdad" 16 .

Se trata del clásico debate entre dirigir o no la fotografía de índole documental. No obstante, el tiempo ha querido poner esta fotografía en el estante de las fotos-icono lo cual indica que, dirigida o ligeramente manipulada, se trata de una imagen que representa el sufrimiento real de una madre que no tiene nada, ni siquiera comida que ofrecer a sus hijos ${ }^{17}$. Dorothea Lange describe así el momento de la toma de la instantánea: Vi aquella madre hambrienta y desesperada y me acerqué como atraída por un imán. No recuerdo cómo le expliqué mi presencia o la de mi cámara, pero sí recuerdo que ella no me preguntó nada. Hice cinco tomas, trabajando cada vez mas cerca desde la misma dirección. No le pregunté su nombre ni por su historia. Ella me dijo su edad, treinta y dos años. Dijo que habian estado comiendo verduras heladas de los campos cercanos, y pájaros que cazaban los niños. Había vendido incluso las cubiertas de las ruedas de su coche para comprar comida. Alli estaba, sentada en aquella tienda de campaña con sus hijos acurrucados a su alrededor, y parecía pensar que mis fotos podrían ayudarla, y así ella me ayudaría a mi. Había una cierta equidad en aquello ${ }^{18}$. Sin embargo, la madre protagonista de aquella foto, identificada posteriormente como Florence Owen Thompson dijo: Ojalá nunca me hubiese hecho esa foto. No obtuve provecho alguno de ella. Ella ni siquiera me preguntó mi nombre. Me dijo que nunca vendería aquellas fotos y que me enviaría una copia, pero nunca lo hizo ${ }^{19}$. Parece ser que se trata de un caso muy diferente a la mayoría de fotos consagradas como icono tomadas por otros reporteros gráficos. En muchos casos, esas instantáneas no solo han conseguido pasar a la historia sino que lograron ayudar al protagonista de la foto y en la mayoría de los casos, víctima. Sin embargo, al convertirse esta fotografía en símbolo de todos aquellos emigrantes norteamericanos sirvió como denuncia generalizada y cómo modo para mostrar, al estilo de Jacob Riis, cómo vive esa otra mitad.

Hubo otras muchas fotografías famosas de Dorothea que nos ilustran la memoria de la Gran Depresión americana pero también la situación de los japoneses americanos, o nisei, tras el ataque de Pearl Harbour en diciembre de 1941 y que fueron evacuados por la War Relocation Authority a campos de concentración situados en la costa oeste norteamericana.

\footnotetext{
${ }^{16}$ DURDEN, Mark: Dorothea Lange. New York, Phaidon, 2006 pág. 38

${ }^{17}$ Ibíd. P. 38

${ }^{18}$ LANGE, Dorothea: The Assignment I'll Never Forget: Migrant Mother. Popular Photography 46:2 (February 1960):42.

${ }^{19}$ DUNN Geoffrey: "Photographic License." New Times: San Luis Obispo (2002) Disponible en Internet: http://web.archive.org/web/20020602103656/http://www.newtimesslo.com/archives/cov_stories_2002/cov_01172002.html [Consultado el 27 de mayo de 2013]
} 
Llegados a este punto, cabe hacer una reflexión muy interesante en cuanto a la fotografía documental siguiendo la línea de Margarita Ledo, y es que este género dio el salto a las revista ilustrada, cuyo boom fue coetáneo a la $F S A$, y le confirió un estilo propio, con fotografías a todo color y con la mayor de las calidades posibles, además de ser un altavoz inigualable para los fotógrafos documentales ${ }^{20}$. Podemos citar aquí el trabajo de Bill Eppridge, Margaret Bourke-White, Alfred Eisenstaedt o Henri Cartier-Bresson. Además, estas revistas ilustradas fomentaron realmente la creatividad de todos estos profesionales de la fotografía, que realizaron reportajes de muy variada índole. ${ }^{21}$

Por otra parte, con la fotografía de conflictos bélicos ocurrió prácticamente igual pues desde el principio tuvo una clara vocación de fotografía documental. De este modo, ¿puede el fotoperiodismo tener un componente claramente documental? Podemos afirmar que sí. La documentación de una guerra, especialmente en nuestros días, está íntimamente ligado al documentalismo a la hora de mostrar qué y por qué ha ocurrido ese conflicto, dónde se ha producido, cuáles han sido sus consecuencias, quién se ha enfrentado, quién ha ganado y quiénes han sido sus víctimas. En efecto, el documentalismo fotográfico nos informa. Por ejemplo, Roger Fenton (1819-1869) considerado por la historiografía como el primer fotoperiodista, fotografió la Guerra de Crimea (1854-1858) ${ }^{22}$ pero también curiosamente documentó el ingente equipo fotográfico que en aquella época llevaban consigo los fotógrafos.

${ }^{20}$ Margarita Ledo recoge también en Documentalismo Fotográfico la clásica dicotomía bellezaverdad tan aplicable en este caso: fotografías creativas que nos muestran una realidad, que son prueba de que ese hecho que ha sufrido todo un proceso desde el clic del fotógrafo hasta que las vemos impresas, muestran, sin duda, una realidad. Y, un tercer componente, que completaría el binomio belleza-verdad que sería la ética: ¿cuándo fotografiar y cómo hacerlo? ¿Puede el fotógrafo inmiscuirse en cualquier realidad con el fin de mostrársela a unos determinados receptores? Abajo cito el trabajo de Bill Eppridge y Mary Ellen Mark que supieron ganarse honestamente la confianza de los sujetos a fotografiar y establecieron incluso, en el caso de Mark, relaciones duraderas en el tiempo con los protagonistas.

${ }^{21}$ Por ejemplo, el aún hoy estremecedor trabajo del ya citado Bill Eppridge publicado el 26 de febrero de 1965, que lleva como título Needle Park en el que pone de relieve el, hasta entonces, desconocido mundo de los adictos de la heroína. Para ello, convivió durante varios días con una pareja de yonkies y se ganó su confianza para fotografiarles mostrando, así, el verdadero infierno en el que vivían. Era una realidad, sin duda, pero una realidad hasta entonces oculta para el gran público, los lectores de esas revistas ilustradas, al igual que veremos con los homeless teenager de Seattle que Mary Ellen Mark nos mostrará en los años ochenta, cuando, curiosamente, esa ciudad se autoproclamaba la mejor ciudad de Estados unidos para vivir.

${ }^{22}$ No obstante, ya existían daguerrotipos de la Independencia de México o de la Revolución de 1848 en París. 


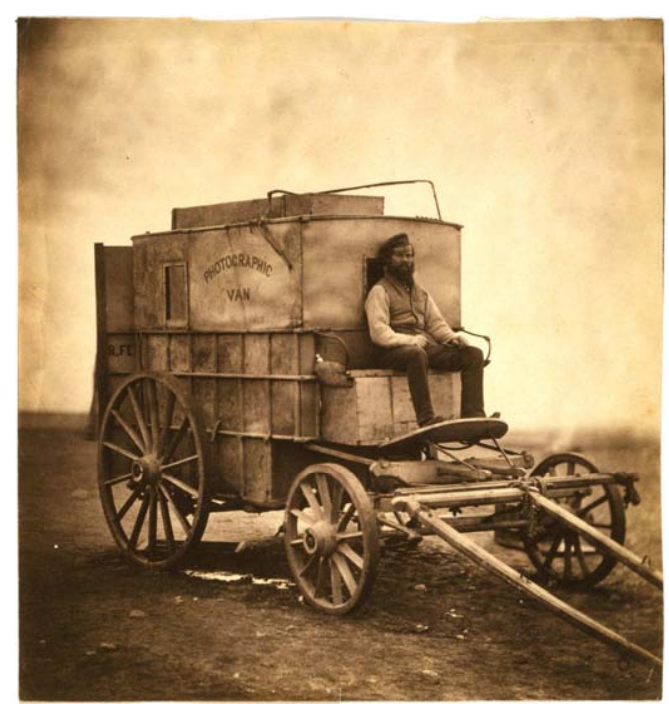

Roger Fenton y William Henry Jackson: Carromato fotográfico de Roger Fenton con Marcus Sparling sentado

Otros de los pioneros en documentar un conflicto bélico fueron Felice A. Beato en la Segunda Guerra Anglo China, más conocida como Guerra del Opio (1856-1860) en la que ya se fotografiaron cadáveres, Mathew Brady (1823-1896), Alexander Gardner (1821-1882), Timothy H. O‘Sullivan (1849-1882) en la Guerra de Secesión Americana (1861-1865) ${ }^{23}$. Y esto solo fue el comienzo pues a partir de estas primeras guerras fotografiadas, todos los demás conflictos contarán con numerosos profesionales que con sus imágenes den fe del horror y las entrañas de esos conflictos. Y, por supuesto, la prensa, en su ascenso a convertirse en el famosos cuarto poder irá cediendo cada vez más espacio a la fotografía documental hasta hacerse indispensable en el mundo del periodismo.

De este modo, es lógico pensar que el documentalismo contemporáneo (que comienza durante la segunda revolución del fotoperiodismo en los años sesenta pero continúa hasta nuestros días) bebe de la herencia del documentalismo que fue conformándose durante el siglo XIX hasta mediados del siglo XX, aunque exista una importante diferencia con aquel, y es que, como señala el profesor Jorge Pedro Sousa: hoy los fotógrafos documentales están probablemente más interesados en conocer y comprender que en transformar el mundo ${ }^{24}$. Esta afirmación se cumple quizá en el caso de Miguel Trillo, sin embargo, en cuanto a Mary Ellen Mark no es así pues continua la senda trazada por los concerned photographers que, según Cornell Capa,

${ }^{23}$ JOHNSON, William S.; RICE, Mark y WILLIAMS Carla: The George Eastman House Collection: Historia de la fotografia: de 1839 a la actualidad. Colonia, TASCHEN, 2012. Pág

${ }^{24}$ SOUSA, Jorge Pedro. Op.cit pág. 210 
hermano de Robert Capa y fundador del neoyorkino International Centre of Photography (ICP) aglutina a aquellos fotógrafos que demostraron en su trabajo un impulso humanitario en el uso imágenes con el fin de educar y cambiar el mundo, además de retratarlo ${ }^{25}$. Entre estos concerned photographers se encontraban el propio Cornell Capa, Bishof, Kertèsz, Leonard Freed, Dan Weiner, y David Chim Seymour ${ }^{26}$.

Para terminar este epígrafe, repasemos algunas de las características del documentalismo fotográfico contemporáneo son: la variedad de temáticas y estilos, a veces muy próximas al arte, la persecución de la subjetividad por encima de la objetividad $^{27}$, respeto por la diversidad cultural y también social, proyectos de larga duración y conciencia por parte del fotógrafos del imaginario colectivo esculpido por los mass media.

\section{EL DOCUMENTALISMO FOTOGRÁFICO EN ESPAÑA. MIGUEL TRILLO, EL FOTÓGRAFO DE LAS TRIBUS URBANAS}

Los años ochenta del siglo pasado supusieron una época de cambios sociales, culturales y económicos en España favorecidos por la recién estrenada democracia y las libertades que ello supuso: de expresión, asociación o reunión, etcétera, que desembocaron en la creación de una nueva sociedad que en muy pocos años pudo ponerse al nivel de otros países mucho más avanzados. En el campo de la política, tras la muerte de Franco, en 1975, Juan Carlos I es proclamado rey de España y se inicia el periodo llamado como "Transición”. Tras el breve gobierno de Arias Navarro (noviembre de 1975 hasta julio de 1976), Adolfo Suárez es nombrado Presidente del Gobierno y el seis de diciembre de 1978 por fin es aprobada la Constitución española. En las elecciones de 1979 vuelve a vencer la UCD de Suárez, aunque la izquierda ganó en numerosos pueblos gracias a la alianza entre el PSOE y el PCE. Desde 1979 hasta 1981, año del famoso golpe de estado, se produce un deterioro del gobierno de Suárez y su dimisión en enero de 1979, debido a causas tales como la brutalidad de los atentados terroristas de ETA, la crisis interna de UCD y la oposición cada vez

\footnotetext{
${ }^{25}$ Definición extraída de la web del ICP y traducida al español del inglés: Those photographers who demonstrated in their work a humanitarian impulse to use pictures to educate and change the world, not just to record it.

${ }^{26}$ SOUSA, Jorge Pedro: Op cit, pág 155

${ }^{27}$ Es decir, el punto de vista del autor por encima del hecho tal cual sucede pues el fotógrafo crea un estilo propio que deja patente en su obra. A veces, incluso, al igual que sucede en el arte podemos ver una evolución en el estilo. Un ejemplo es Sebastiao Salgado, en la línea de los concerned photographers pero con un estilo inconfundible: uso del blanco y negro, contrastes tonales, planos muy abiertos y la orientación horizontal de la imagen.
} 
mayor del PSOE. Además la extrema derecha, cada vez más fuera del juego político, comienza la preparación del Golpe de Estado que tendrá lugar el 23 de febrero de 1981, el día que se votaba por segunda vez la investidura de Calvo Sotelo (UCD).

En 1982, el PSOE gana las elecciones de forma abrumadora y en esta primera legislatura, España entrará en la Comunidad Económica Europea y en la OTAN, además de la aprobación de la LODE que garantiza la enseñanza obligatoria y gratuita hasta los dieciséis años y la despenalización parcial del aborto. Por tanto, como vemos, en muy pocos años, menos de diez, desde que muere Franco hasta que el PSOE llega al poder, se concentran muchos cambios que también tienen su reflejo en la cultura. Y es que ya no hay una "cultura oficial del régimen" y por fin política y cultura caminarán por distintas sendas. Ello es de gran importancia, pues florecerán numerosas tendencias artísticas en pintura, cine, música o moda ${ }^{28}$. Además, se conformará una subcultura, (especialmente integrada por los jóvenes, que tras vivir una dictadura y una transición se encuentran ya de pleno en la democracia): la Movida madrileña. Como señala Héctor Fouce: desaparecida lo dictadura, se da una situación de lucha de cara a establecer un nuevo discurso dominante. El interés por lo politica se va apagando al concretarse el cambio en un marco institucional concreto que desplazo o otras posibilidades, relegadas ahora a ser mera utopía. La movida no se presenta como discurso oposicional, acepto el discurso de normalidad institucional pero se aparta de él, pretende ignorarlo a pesar de tener la necesidad de interaccionar con él ${ }^{29}$.

Este movimiento, si así podemos llamarlo, cambió por completo la perspectiva de una ciudad y, por ende, de un país. Como el propio Miguel Trillo señala fue un quinquenio de oro que no estaba en ningún plan de desarrollo del postfranquismo. Por eso su éxito mediático. Podría parecer que fuimos al revés del mundo occidental. Los libros de Historia hablan de esos años de una vuelta al conservadurismo en el mundo occidental. Ronald Reagan y Margaret Thatcher son los iconos gobernantes. Pero los libros de la historia de la calle dicen lo contrario ${ }^{30}$ Madrid pasa de ser una ciudad gris y mediocre a ser una ciudad efervescente culturalmente hablando. $L a$ Movida se atrevió a hacer todo lo que no se había hecho antes y, en cierto modo, esta cultura underground, ha llegado a formar parte de la cultura en mayúscula de nuestro país. Almodóvar, por ejemplo comenzó su andadura entonces, al igual que la fotógrafa Oukaleele o la cantante Alaska. Además también a partir de este movimiento aparecieron nuevas publicaciones (La luna de Madrid o Madrid me

\footnotetext{
${ }^{28}$ Por fin se gesta en nuestro país corrientes que ya habían triunfado en otros países como el pop-art de la mano del Equipo Crónica o Eduardo Arroyo; en otros campos como el cine, España ganará su primer Oscar con la inolvidable Volver a empezar de José Luis Garci en 1983, y en música se vivirá la Edad de Oro del pop español con grupos como Alaska y los Pegamoides, Mecano o Los secretos, que aún hoy en día siguen influyendo en nuevos grupos y cantantes.

${ }^{29}$ FOUCE Héctor: La cultura juvenil como fenómeno dialógico: reflexiones en torno a la movida madrileña en CIC Cuadernos de Información y Comunicación; Número 5, 2000; págs. 267-275

${ }^{30}$ Entrevista inédita realizada por la autora a Miguel Trillo
} 
Mata), o nuevos estilos en fotografía, aportando nuevos temas como veremos a continuación con Miguel Trillo.

Miguel Trillo nace en Jimena de la Frontera, Cádiz, en 1953 donde vive con su familia hasta los quince años, cuando se trasladan a Málaga. Algunos años después, Miguel Trillo decide dejar su hábitat doméstico y marchar a la capital española para estudiar en la Universidad Complutense de Madrid. Al terminar su licenciatura en Filología Hispánica inicia los estudios de Imagen en la Facultad de Ciencias de la Información, aunque terminará esa carrera siendo ya siendo profesor de Lengua y Literatura en un instituto: fue una licenciatura de adorno -nunca llegué ni a recoger el título- porque sabía que además de que no era necesaria para hacer cine, vi que nunca dirigiría una película, que yo no servía para la creación coral, que yo era un creador solitario y la cámara fotográfica era mejor herramienta para ello, junto al papel para la escritura. Eran dos vocaciones complementarias. En mi casa habia máquina de escribir, pero no máquina fotográfica. Hasta los 19 años no tuve ninguna cámara. Fue una cámara compacta de pésima calidad. Y con 23 años como fin de carrera de Filología me regalaron una cámara réflex en condiciones, asi que hasta 1976 no nazco de verdad como fotógrafo, muy tardíamente. Al principio practicaba una fotografía literaria, escenificaciones fantasiosas a lo Duane Michals o surrealistas influenciadas más por los anuncios de las revistas médicas que le llegaban a mi padre que por la revista Nueva Lente, que no llegué a conocer hasta 1978. Y poco a poco mi tiempo se iba llenando de fotos y mis textos empezaban a perder peso vocacional. Mi obra literaria favorita de aquel momento era Pedro Páramo del mexicano Juan Rulfo, curiosamente un escritor fotógrafo ${ }^{31}$.

En Madrid vivirá y desarrollará gran parte de su trabajo fotográfico hasta 1994 cuando se traslada a Barcelona aunque lo cierto es que Trillo ha documentado fotográficamente a los jóvenes de casi todas las Comunidades Autónomas de nuestro país en muchos otros períodos o épocas. Sus clics o disparos han captado estéticamente y antropológicamente una subcultura urbana y rural: las tribus urbanas en un proyecto de investigación visual, cuya trama se rige, paradójicamente, por un hilo conductor sonoro ${ }^{32}$. Y sus propias palabras corroboran lo anterior: Cada foto que hago tiene una canción, una melodía ${ }^{33}$. Parece lógico que, llegados a este punto, recordemos otra fotógrafa cuyas imágenes llevan implícitas el ritmo y el verso del recién nacido, por aquel entonces, hip-hop neoyorkino: Martha Cooper ${ }^{34}$. No obstante, mientras que Martha Cooper se centra en una sola tribu urbana, aunque nos muestra variaciones del mismo, como por ejemplo el mundo del el graffiti y del

31 Íbidem

${ }^{32}$ GALLERO, José Luis: Miguel Trillo. La felicidad del pescador. Biblioteca de Fotógrafos Españoles. Alcobendas, TF Editores. 1999. Pág. 4

${ }^{33}$ GARCÍA, David: Miguel Trillo: Cada foto que hago tiene una canción, una melodía. Yorokobu (2013) Disponible en Internet en http://www.yorokobu.es/migueltrillo/ [Consultado el 18 de mayo de 2013]

${ }^{34}$ COOPER, Martha: Hip Hop Files: Photographs 1979-1984, From Here to Fame, Alemania. 2004. 
break-dance, Miguel Trillo abarca todas las tribus, quiere mostrar al espectador un pedazo de los gustos de los jóvenes españoles en un momento de la historia de España clave, pues se dejaban atrás cuarenta años de represión. En cualquier caso, podemos encontrar un punto común en ambos fotógrafos: el deseo de registrar, documentar una subcultura y dotarla de una importancia que la sociedad hasta entonces no le daba ${ }^{35}$. Pero, ¿con qué tribu urbana se siente Miguel Trillo más identificado? Mis simpatías mayores han sido para los mods. Tal vez porque el revival mod tras la película Quadrophenia (1979) que vivi en Madrid me remitía a mi preadolescencia, que es cuando se es más fanático de la música. Me marcaron canciones de The Kinks, Beatles, Who, Rolling que llegaban a mi pueblo por la radio (gracias a su cercanía con Gibraltar) más la de grupos españoles como Brincos, Bravos, Canarios y demás que estaban empapados de ese pop-rock visceral que venía de Londres. Aunque tengo que reconocer que también en el Madrid de los 80 disfruté con conciertos de heavy o de hip hop por el espectáculo que se formaba. Y si tuviera que elegir con la cabeza, la música electrónica y la ola siniestra me satisfacían muchísimo. Nunca he ido a un concierto a pasarlo mal. Y no he consumido, por ejemplo, música clásica. Tampoco flamenco, a pesar de ser andaluz. Son músicas que valoro pero no me han atraído. ${ }^{36}$

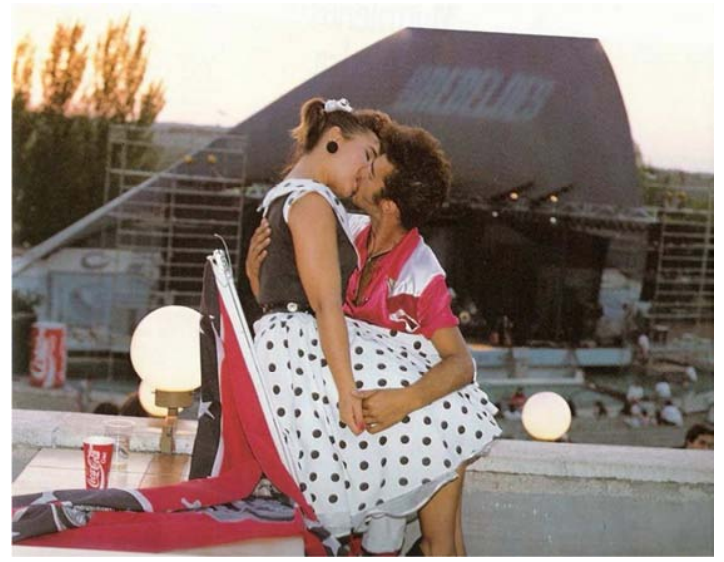

Rockers, Madrid, 1991

Al descomponer, desmontar o "deconstruir" las fotografías de Trillo encontramos dos planos opuestos pero accesorios por necesidad: en primer lugar, los protagonistas

\footnotetext{
${ }^{35}$ De hecho, en el caso de Martha Cooper estaba claro que se trataba de una subcultura marginal en aquel momento, que eran los años setenta y ochenta del pasado siglo veinte, erróneamente quizás asociada al mundo de la delincuencia y las drogas, especialmente en la escena neoyorkina como se puede observar en films como Beat Street (Stan Lathan, 1984).

${ }^{36}$ Entrevista inédita realizada por la autora a Miguel Trillo.
} 
que suelen ser jóvenes como ya se ha señalado de una determinada tribu urbana y que el espectador puede percibir superficialmente como hedonistas. Pero en un segundo plano, está la intención/necesidad profunda del autor, de Miguel Trillo que no es otra que hacer un trabajo antropológico para la posteridad y dar voz a subculturas, como ya hacían Curtis y Vroman con los nativos del lejano oeste americano en el siglo XIX ${ }^{37}$. Y lo más interesante, el encuadre de las fotografías dejan el espacio suficiente para ver dónde el sujeto se desenvuelve, que nos aportan el significado necesario para terminar de comprender la fotografía: rockeros con el escenario del Parque de Atracciones de Madrid detrás o mods sentados en una Vespa. Él mismo describe el proceso para realizar una fotografía así: En mi fotografia busco belleza. Si no hay belleza, no me vale. Y tampoco, si no hay intencionalidad. Me considero un fotógrafo clásico de una escuela que se remontaría a August Sander. Añado una filosofia moderna, digamos de disfrute. Cuando encuentro a una persona que quiero fotografiar, necesito encuadrarla en un fondo acorde para que haya diálogo (...) Veo mi obra como un crucigrama no de palabras, sino de miradas. A veces sigo por la sala a la persona que quiero retratar y no le entro hasta que veo que se está acercando a uno de los espacios que me gustan. Y otras veces es al revés, elijo el sitio y me quedo alli esperando que pase alguien que yo vea de interés fotogénico.(...) Prefiero una fotografia construida y tranquila en medio de ese ruido y entre tanto frenesí. Y en esto que me cuelo yo como autor. También busco que haya una actitud en la ropa, en la mirada sin gastar y que al no ser una estrella, lo parezca ${ }^{38}$. Curiosamente, ocurre lo mismo con Mary Ellen Mark, de la que hablaremos en el punto tres de este artículo y su fotografía de Tiny en Halloween: en realidad se trata de una niña de la calle, pero la autora ha conseguido lo mismo que Miguel Trillo, es decir, que parezca una estrella sin serlo.

Como señala José Manuel Costa cada foto de Trillo también retrata el instante de unos jóvenes en un instante histórico ${ }^{39}$ y por supuesto, todavía Trillo es registrador de la juventud contemporánea. No obstante, reconoce que ese registro ha ido cambiando al mismo ritmo que la tecnología: desde el cambio de la cámara réflex analógica a la digital pasando por el smartphone con el que repite las instantáneas tomadas con su cámara a petición de los fotografiados. Para que quede constancia.

\footnotetext{
${ }^{37}$ Véase punto 1 del presente artículo.

${ }^{38}$ CULLA Noemí: La visión provocada de Miguel Trillo. Camara Magazine (2013) Disponible en Internet en: http://www.camaramagazine.com/index.php/magazine/visiones/item/1470-la-visionprovocada-de-miguel-trillo [Fecha de acceso 27 de mayo de 2013]

${ }^{39}$ COSTA, José Manuel: texto para la exposición “Complicidades. Retratos 1976-2011” organizada en Málaga por Unicaja en 2011.
} 


\section{MARY ELLEN MARK Y LOS HOMELESS TEENAGERS DE SEATTLE}

Estados Unidos en los años ochenta ya había confirmado su status de superpotencia mundial, pero es en esta década cuando hará patente también su supremacía tecnológica. Es la década en la que Apple y Windows inician su andadura y el tres de enero de 1983, la revista Time nombró al ordenador "la máquina del año" 40. En cualquier caso, es también década del "nuevo conservadurismo" en la que Ronald Reagan, del partido republicano, desarrollará su mandato (1981-1989) en el que las relaciones con el bloque comunista serán tensas hasta 1984, debido a incidentes como la supresión del movimiento sindical polaco "Solidaridad" en 1981 y el derribo del avión civil de Korean Airlines que se salió de curso por parte de un caza soviético en 1983. Sin embargo, en la segunda mitad de la década y gracias a acuerdos como el Tratado sobre Fuerzas Nucleares de Alcance Intermedio en 1987, esta tensión entre las dos potencias se fue relajando, hasta el fin de la Guerra Fría en 1989, ya durante el mandato de Bush.

Por otro lado, es en 1981 cuando se descubre el SIDA (Síndrome de Inmunodeficiencia Adquirida) que se cebó especialmente con el colectivo gay y con los adictos a drogas inyectables ${ }^{41}$. Esta enfermedad pronto se extendió por casi todos los países y se convirtió en la peor enfermedad del siglo pasado. Por otro lado, en cuanto al colectivo gay, durante los años ochenta fueron derogadas muchas leyes discriminatorias que anteriormente les afectó y algunos estados promulgaron leyes contra la discriminación. En cuanto a la cultura, debido al cambio en las políticas migratorias en 1965 y a la entrada en Estados Unidos de inmigrantes hispanos, se produce una gran influencia latina, especialmente en la música. Es el surgimiento de la industria de la música pop, cuyos máximos exponentes serán Madonna, Michael Jackson o el nuevo canal de televisión MTV que comenzó a emitir en 1981, y que se convertirán en el estandarte de millones de jóvenes del mundo. No obstante, como veremos a continuación, la vida de los adolescentes del submundo retratado por Mary Ellen Mark en las calles de Seattle será completamente diferente.

Mary Ellen Mark ya había realizado numerosos reportajes antes de Streets of the lost en 1983, que la situaban como una importante fotógrafa documental con un estilo propio bastante definido. Sin ir más lejos, en 1978 realizó el fotorreportaje Ward 81, publicado como libro en 1979, en el que retrató las duras condiciones de vida de las mujeres ingresadas en un hospital mental de alta seguridad de Oregón en el que dejó patente su estilo: fotografías en blanco y negro, empatía con el fotografiado (incluso, como veremos, amistad duradera en el tiempo) y un tratamiento del sujeto fotografiado extraño, incómodo y atractivo para el receptor, con el que establece una

\footnotetext{
${ }^{40}$ Portada de Time del tres de enero de 1983, disponible en: http://www.time.com/time/ covers/0,16641,19830103,00.html [Fecha de consulta: 20 de mayo de 2013]

${ }^{41}$ De hecho, Patti una de las adolescentes retratadas por Mary Ellen Mark en las calles de Seattle, falleció a causa de esta enfermedad.
} 
conexión, un enganche emocional el cual consigue no sólo que no aparte la mirada ante escenas con un trasfondo desagradable, sino que es capaz de hacerle sentir empatía con el fotografiado y la necesidad de saber más acerca de él.

Un par de años después, en 1981, Mark publicaría Falkland Road: Prostitutes of Bombay donde, a todo color, lo cual es inusual en su obra, da fe de las condiciones de vida de las prostitutas de la ciudad India de Bombay: niñas de doce años, madames, clientes, travestis y prostíbulos a veces lujosos y otras veces miserables, como las vidas de estas prostitutas. Y, de nuevo, la empatía fotógrafo-fotografiado-receptor. ${ }^{42}$

Sin embargo, el trabajo de Mary Ellen Mark que aquí nos ocupa es el del reportaje para la revista Life Streets of the lost. Mary Ellen Mark ya había trabajado anteriormente para esta revista, en concreto desde los años sesenta realizando regularmente fotorreportajes para esta publicación que, en esta ocasión, le encargará visitar Seattle the most livable city, junto a la periodista, hoy tristemente fallecida, Cheryl Mccall, y así realizar un reportaje en el que se mostrase la verdadera realidad de esa ciudad estadounidense. Y la realidad era que numerosos adolescentes se buscaban la vida en las calles de Seattle, concretamente en Pike Street, muy cerca del centro.

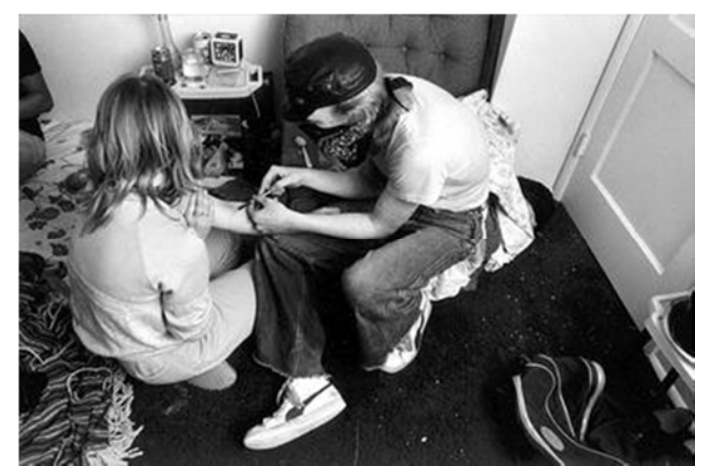

Fotografia extraída del reportaje Street of the lost. Seattle, 1983

Jóvenes, casi niños, pues su edad se situaba en la franja de edad que va desde los doce a los dieciséis años, que robaban, se drogaban, se prostituían, vendían plasma y, en fin, malvivían de puertas a una sociedad que básicamente les obviaba. Eran chicos que se habían fugado de casa debido a abusos pero también que habían sido expulsados de sus hogares por mal comportamiento, tal es el caso de Mike y Rat,

\footnotetext{
${ }^{42}$ Otro bello ejemplo de esta temática y de la empatía, sobre todo con el sujeto retratado, son las instantáneas que Patrick Zachmann realizó a prostitutas adolescentes de Bangkok en 1991 y disponibles aquí http://www.teenagefilm.com/archives/archive-fever/bangkok-teen-prostitutes-1991/
} 
originarios de California y excelentes estudiantes antes de vivir en la calle ${ }^{43}$. También se nos cuenta la historia de Patti, Christy, Sam, Shadow o Erin Tiny quien se convertirá en el símbolo de todos ellos. Y es que tras el impacto que causó este reportaje, Martin Bell, director de documentales y marido de Mark, volvió junto a su mujer y Cheryl Mccall a Seattle, y rodaron el documental Streetwise ${ }^{44}$ en el que los adolescentes se mostraron de nuevo muy abiertos y dispuestos a mostrar su vida. Durante el rodaje, Mary Ellen Mark tomó de nuevo fotografías de los protagonistas y publicó en 1988 el extraordinario libro del mismo nombre (Streetwise) donde profundiza en el miserable modo de vida de estos adolescentes centrándose en Tiny, que se convirtió en la estrella del documental, en el hilo conductor, una especie de celebrity que incluso asistió a la gala de los Oscar de 1984 junto a Mark y Bell, y a la que ofrecieron un papel en Hollywood que rechazó. Mary Ellen Mark cuenta que la conoció en los alrededores de una discoteca de Seattle y en un primer momento pensó que solo tenía doce años, aunque contaba con catorce. Vestía ropa muy ajustada e iba demasiado maquillada por lo que parecía una niña disfrazada ${ }^{45}$. Ese fue el comienzo de una larga relación que continua hasta hoy: Sigo en contacto con Tiny. Hace un par de años Martin y yo volvimos a Seattle y nos pusimos al día sobre su vida. Y la he ido fotografiando, aunque no he estado alli desde hace tres años. La fotografié cuando tuvo su noveno hijo, pero no pudimos ir cuando dio a luz al décimo ${ }^{46}$. Incluso en el año 2006, Bell realizó un corto sobre su vida mostrando su vida desde los años noventa hasta la década de los dos mil.

Quizá otra de las características de la fotografía de Mark es que sus fotografías, pese a estar retratando miseria tienen algo de fotografía de moda. Y ello no sólo lo vemos en la serie de fotografías que tomó de los adolescentes de Seattle, sino también en las recogidas en el libro American Odissey, un recopilatorio de fotografías tomadas a lo largo y ancho de Estados Unidos entre 1963 y 1999.

\footnotetext{
${ }^{43}$ Extraído del propio reportaje Streets of the lost. Disponible en la página web personal de Mary Ellen Mark: http://www.maryellenmark.com/text/magazines/life/905W-000-021.html [Fecha de consulta 21 de mayo de 2013]

${ }^{44}$ Nominado al Oscar en la categoría de Mejor documental en 1984 y ganador del Premio Especial del Jurado del Festival de Sundance en 1985.

${ }^{45}$ Información acerca del film disponible en la página web personal de Mary Ellen Mark: http://www.maryellenmark.com/films/titles/streetwise/streetwise_home_page.html

${ }^{46}$ LAFRENIERE Steve: Mary Ellen Mark. Vice.com (2009) Disponible en Internet en: http://www.vice.com/es/read/mary-ellen-mark-144-v2n7 [Fecha de consulta 25 de mayo de 2013]
} 


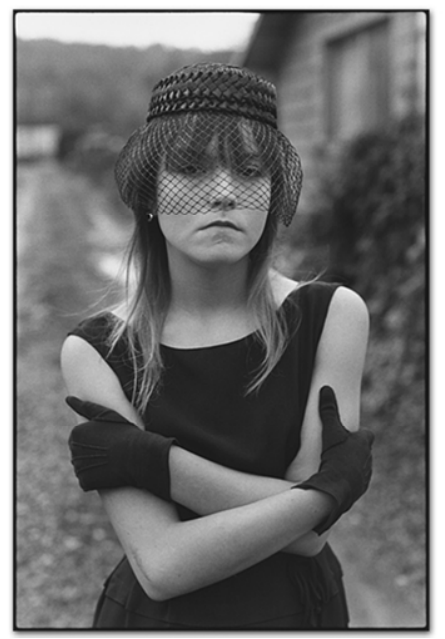

Tiny en Halloween. Seattle, 1983

Acerca de esta icónica foto, Mary Ellen Mark señala: Es extraño cómo algunas imágenes perduran. No sé, supongo que tiene algo que ver con su rostro y con el sombrero. Era muy guapa. Es una de las fotos más sencillas que he hecho, casi como una fotografia de moda. Pero es de verdad ${ }^{47}$.

\section{CONCLUSIONES}

Tanto Miguel Trillo como Mary Ellen Mark nos muestran a su manera cómo vive una juventud determinada, en un lugar determinado y en una época determinada. Mientras que el primero muestra unos jóvenes a todo color en un país que pocos años antes era completamente gris, Mark escoge una realidad muy gris en un país donde el consumo, el pop y la publicidad nos regalaban una imagen de una sociedad de colores. La importancia de ambos, salvando las distancias, es la forma de llevar a cabo su propósito y el tratamiento tan acertado de la fotografia. Hay cierta belleza en las fotografías de Mary Ellen Mark, como ya hemos señalado, pero también toda la tristeza de un grupo de niños obligados a prostituirse para comer pero también para poder ir a discotecas, como hacen otros adolescentes. En sus fotografías de las calles de Seattle vemos niños que se debaten entre tener catorce años y aparentar muchos más, la contradicción de dormir con un peluche y venderse a un extraño. Por supuesto, estas fotografías, este estilo y esta temática nada tienen que ver con las de Trillo, superficiales si nos quedamos en la primera capa, y retrato generacional si vamos más allá. Ambos fotógrafos pertenecen a un mismo tiempo y a un mismo

\footnotetext{
${ }^{47}$ Ibídem http://www.vice.com/es/read/mary-ellen-mark-144-v2n7
} 
género cuya principal característica, que podemos certificar que se cumple, es la diversidad de temas e intereses con un sello de autor que hace a sus fotografías inconfundibles y perdurables en el tiempo.

\section{BIBLIOGRAFÍA}

BECEYRO, Raúl: Ensayos sobre fotografía. Buenos Aires, Paidós, 2003.

BULL, Stephen; ALONSO TERRÉ, Laura y LEBRERO STALS, José: Miguel Trillo: Identidades [exposición, Centro Andaluz de Arte Contemporáneo, Sevilla, del 23 de abril al 5 de julio de 2009; Sala de Exposiciones Canal de Isabel II, Madrid, del 16 de septiembre al 15 de noviembre de 2009] Sevilla, Consejería de Cultura, 2009.

COSTA, Joan: El lenguaje fotográfico. Madrid, Ibérico Europea de Ediciones, 1977.

COOPER, Martha: Hip Hop Files: Photographs 1979-1984, From Here to Fame, Alemania. 2004

DURDEN, Mark: Dorothea Lange. New York, Phaidon, 2006

ESTEBAN RECIO Asunción.[et. al.]: Memoria de la Transición. Valladolid, Universidad de Valladolid, 2010.

FREUND, Gisèle: La fotografía como documento social. Barcelona, Gustavo Gili, 2002.

GALLERO, José Luis: Miguel Trillo. La felicidad del pescador. Biblioteca de Fotógrafos Españoles. Alcobendas, TF Editores.

GUARDIOLA, Juan: El imaginario Colonial, fotografía en Filipinas durante el periodo español 1860-1898 Barcelona: Sociedad Estatal para la Acción Cultural Exterior de España, 2006.

HAGEN, Charles. Mary Ellen Mark. London: Phaidon, 2006.

JOHNSON, William S.; RICE, Mark y WILLIAMS Carla: The George Eastman House Collection: Historia de la fotografia: de 1839 a la actualidad. Colonia, TASCHEN, 2012.

LEDO, Margarita: Documentalismo fotográfico: Éxodos e identidad. Madrid, Cátedra. 1998.

LEMUS LÓPEZ, Encarnación: Estados Unidos y la Transición española: entre la revolución de los claveles y la marcha verde. Madrid, Sílex ; Cádiz UCA, Servicio de Publicaciones, 2011.

NEWHALL, Beaumont: Historia de la Fotografía. Barcelona, Gustavo Gili 2002.

SOUGEZ, Marie Loup (coord.): Historia General de la Fotografía Madrid, Cátedra, 2007.

SOUSA, Jorge Pedro: Historia del fotoperiodismo occidental. Sevilla, Comunicación Social, 2003. 


\section{Artículos de Revistas}

VIDAL-BENEYTO, José: Almodóvar. Transición, Posfranquismo, Movida. El Viejo Topo; Número 263, 2009.

DEWEY, Donald: Jacob Riis: Social Reformer. Scandinavian Review, ISSN 0098857X, Volumen 94, Número 2, 2006.

FOUCE Héctor: La cultura juvenil como fenómeno dialógico: reflexiones en torno a la movida madrileña en CIC Cuadernos de Información y Comunicación; Número $5,2000$.

TOBIN, Jacqueline. Mary Ellen Mark, updated. Photo District News, 31(4), 2011.

\section{Webgrafía}

CULLA Noemí: La visión provocada de Miguel Trillo. Camara Magazine (2013) Disponible en Internet en: http://www.camaramagazine.com/index.php/magazine/ visiones/item/1470-la-vision-provocada-de-miguel-trillo [Fecha de acceso $27 \mathrm{de}$ mayo de 2013]

DUNN Geoffrey: Photographic License. New Times: San Luis Obispo (2002) Disponible en Internet: http://web.archive.org/web/20020602103656/ http://www.newtimes-slo.com/archives/cov_stories_2002/cov_01172002.html [Consultado el 27 de mayo de 2013]

GARCÍA, David: Miguel Trillo: Cada foto que hago tiene una canción, una melodía. Yorokobu (2013) Disponible en Internet en http://www.yorokobu.es/migueltrillo/ [Consultado el 18 de mayo de 2013]

ROJAS, Alberto: Kong Nyong, el niño que sobrevivió al buitre ElMundo.es (2011) Disponible en Internet en http://www.elmundo.es/elmundo/2011/02/18/ comunicacion/1298054483.html [Consultado el 16 de mayo de 2013]

Time Magazine del tres de enero de 1983, disponible en: http://www.time.com/ time/covers/0,16641,19830103,00.html

[Fecha de consulta: 20 de mayo de 2013]

Life Magazine (reportajes de Bill Eppridge, Nina Leen, etcétera) http:/life.time.com/ [Fecha de consulta abril-mayo 2013]

Mary Ellen Mark Web http://www.maryellenmark.com [Fecha de consulta abrilmayo 2013]

Blog incluido en la web de la película basada en el libro de Jon Savage "Teenage" http://www.teenagefilm.com/blog [Fecha de consulta abril-mayo 2013]

\section{Otras fuentes}

Entrevista inédita realizada por la autora a Miguel Trillo. 